\title{
Noise in Load Cell Signal in an Automatic Weighing System Based on a Belt Conveyor
}

\author{
Kyoo Nam Choi \\ Department of Information and Telecommunication Engineering, Incheon National University, Incheon 22012, Republic of Korea \\ Correspondence should be addressed to Kyoo Nam Choi; knchoi@inu.ac.kr
}

Received 23 April 2017; Revised 23 June 2017; Accepted 12 July 2017; Published 8 August 2017

Academic Editor: Stephane Evoy

Copyright ( 2017 Kyoo Nam Choi. This is an open access article distributed under the Creative Commons Attribution License, which permits unrestricted use, distribution, and reproduction in any medium, provided the original work is properly cited.

\begin{abstract}
Noise in load cell signal in an automatic weighing system based on a belt conveyor has been examined experimentally in time and frequency domains to enhance signal quality. The noise frequency spectrum showed nonlinearly increasing multiple resonance peaks as speed increased. The noise reduction process using noise reduction algorithm, by sharply rejecting peak noise frequency component and afterward forming optimum pulse width ratio through filter slope control using selective switching of 6 LPF stages, was used for enhanced accuracy. The effectiveness of proposed method, controlling both cutoff frequency and slope of LPF, was evaluated by feeding $50 \mathrm{~g}$ test mass, and this noise reduction process showed better noise filtering with enhanced accuracy than fixed cutoff frequency control method. The ratio of top to bottom pulse width showed that LPF cutoff frequency above $5 \mathrm{~Hz}$ had the ratio above $50 \%$ up to $80 \mathrm{~m} / \mathrm{min}$ speed range.
\end{abstract}

\section{Introduction}

The conveyor belt is widely used, for sensing application, to measure continuously the physical parameters of an object in many fields [1]. The vision sensors are used for tracking and identifying an object moving on a conveyor belt [24], and range sensors are used for volume measurement [5]. The automatic weighing and sorting system is used in food and pharmaceutical industry where continuous and precise mass measurement of small objects is required [6,7]. The belt conveyor is used for automatic weighing to continuously feed products under measurement [8-12]. However the horizontal and rotational movements of belt conveyor eventually cause vibration [13], and these behave as noise source to the output of load cell sensor $[14,15]$. High signal-to-noise ratio (SNR) is needed to improve accuracy and resolution of weighing machine; thus noise reduction is essential process [16-19]. The electric motor, AC induction or BLDC motor, is used to actuate belt conveyor [20-22], which has different vibration characteristics. Also other individual components of belt conveyor, such as bearing, belt, and roller, with accompanying vibration, transfer noise to load cell sensor [23]. The way to reduce the vibration noise of belt conveyor has been investigated [24, 25], and the method to locate the fault point in belt conveyor has been attempted by analyzing audible signal from belt conveyor [26, 27]. Also the investigation to driving motor to reduce the noise was conducted [28]. The work to improve accuracy through modeling has been performed for weighing machine adapting belt conveyor [29]. Further efforts to enhance continuous measurement accuracy for high speed mass measurement have been performed [30, 31]. In respect of analysis method, the algorithm adapting frequency analysis $[32,33]$ or digital filter [34] was attempted. In this paper, the noise in load cell signal in an automatic weighing system based on a belt conveyor is analyzed, and the method to reduce the noise component in load cell sensor is investigated.

\section{Vibration Noise Analysis}

Noise, $Y_{X}(t, x)$, from belt conveyor contains not only the operating vibration but also the environment noise, as shown in (1). The environment noise, $N_{X}(t, x)$, has the characteristics of either white noise or nonstationary process; however the operating vibration, $S_{X}(t, x)$, has the characteristics of wide sense stationary process. These noises from individual components of belt conveyor can be analyzed in time domain and frequency domains. The objective of this study is to 


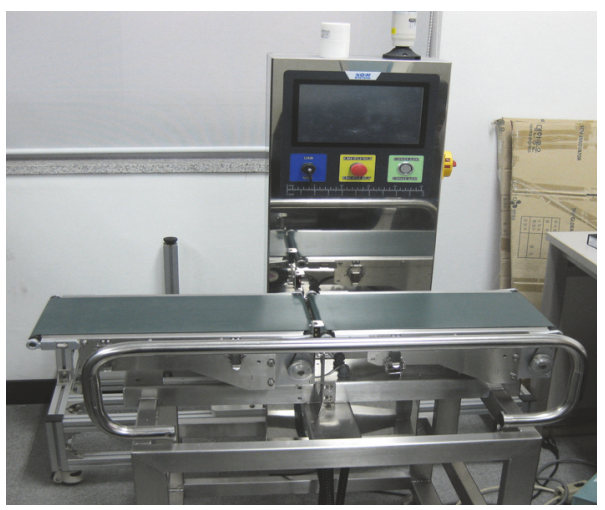

(a)

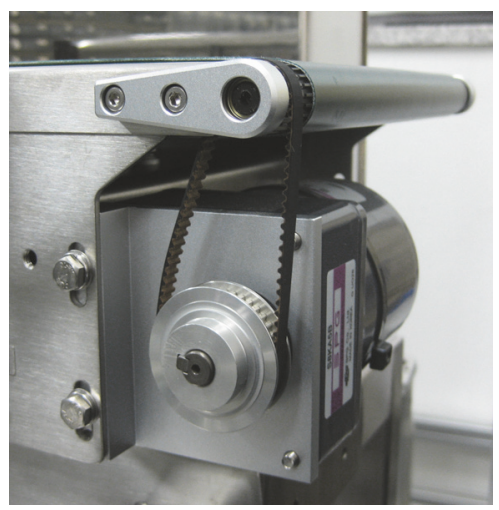

(b)

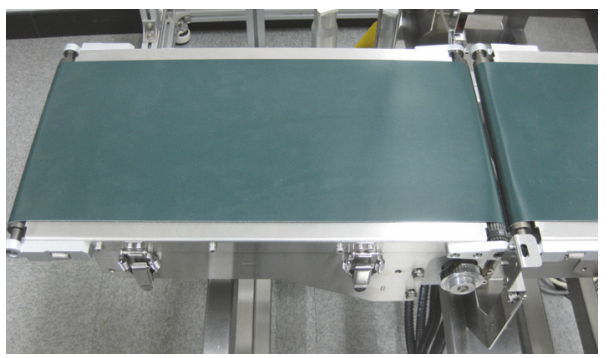

(c)

Figure 1: Measurement setup. (a) Weighing machine. (b) Pulley. (c) Belt conveyor.

reduce the noise from operating vibration by analyzing noise components through actual measurement.

2.1. Noise Components from Operating Vibration. The main components of noise $S_{X}(t, x)$ are influenced by the length of conveyor, $l_{C}$, the radius of belt pulley, $r_{p}$, the number of toothed belt pulley's teeth, $n_{p}$, and the number of toothed motor pulley's teeth, $n_{m}$, in terms of elapsed time, $t$, and motor axis position, $x$. Fourier transform of noise $S_{X}(t, x)$ can be decomposed into the noise from belt conveyor, $B_{X}(f, x)$, the noise from belt pulley, $P_{X}(f, x)$, and the noise from driving motor, $M_{X}(f, x)$, in terms of frequency, $f$, and position, $x$, as shown in (2). Fourier transform of noise $N_{X}(t, x)$ can be expressed as random variable, $C$, as shown in (3).

$$
\begin{aligned}
Y_{X}(t, x) & =S_{X}(t, x)+N_{X}(t, x), \\
\mathfrak{J}\left(S_{X}(t, x)\right) & =B_{X}(f, x)+P_{X}(f, x)+M_{X}(f, x), \\
\mathfrak{I}\left(N_{X}(t, x)\right) & =C .
\end{aligned}
$$

The originating fundamental noise frequency, $f=R_{\mathrm{rpm}} /$ 60 , is from driving motor revolution per minute, $R_{\mathrm{rpm}}$. The consequential noise components, which are random process, can be represented in terms of $f$, if we fix $x$ to a particular value, with corresponding magnitude, $a_{n}$, as follows. In case we represent above expression in terms of belt speed, $v_{c}, f$ is replaced by $f=\left(1 / 2 \pi r_{p}\right)\left(n_{p} / n_{m}\right) v_{c}$. Parameters which are used in the experiment are as in Table 1. However the resonance between each noise components and physical
TABLE 1: Belt conveyor parameters.

\begin{tabular}{lc}
\hline Symbol & Value \\
\hline$R_{\text {rpm }}$ & $1800 / \mathrm{N}$ \\
$f$ & $30 \mathrm{~Hz} / \mathrm{N}$ \\
$r_{p}$ & $9 \mathrm{~mm}$ \\
$n_{p}$ & 20 \\
$n_{m}$ & 40 \\
$l_{C}$ & $300 \mathrm{~mm}$ \\
\hline
\end{tabular}

structure makes constructive and destructive interference; thus it needs to be verified through actual measurement.

$$
\begin{aligned}
B(f) & =a_{1} \frac{l_{c}}{\left(2 \pi r_{p}\left(n_{m} / n_{p}\right) f\right)}, \\
P(f) & =\left(a_{2}+a_{3} n_{p}\right) \frac{n_{m}}{n_{p}} f, \\
M(f) & =\left(a_{4}+a_{5} n_{m}\right) f .
\end{aligned}
$$

2.2. Measurement of Noise from Belt Conveyor. Noise has been measured in time and frequency domains by using belt conveyor, having $200 \mathrm{~mm}$ width, of automatic weighing machine as shown in Figure 1. Signal and noise are picked up at the load cell, having $3 \mathrm{~kg}$ rated capacity, and amplified 1,000 times before ADC (analog to digital conversion). The belt conveyor speed was varied from $10 \mathrm{~m} / \mathrm{min}$ to $80 \mathrm{~m} / \mathrm{min}$, which is equivalent to $167 \sim 1,333 \mathrm{~mm} / \mathrm{sec}$ or to $f=1.48 \sim$ 
$11.8 \mathrm{~Hz}$, and the received waveform was measured at the test point before ADC. From (4) (6), we can induce that noise spectrum lies in the frequency range between $f$ and its harmonic frequencies; however it will be hard to figure out noise spectrum unless measured experimentally.

Typical snap shot waveforms at the belt conveyor speed of $20 \mathrm{~m} / \mathrm{min}, 50 \mathrm{~m} / \mathrm{min}$, and $70 \mathrm{~m} / \mathrm{min}$ are shown in time and frequency domains as shown in Figure 2. Time domain waveforms are shown in $50 \mathrm{mV} / \mathrm{div}, 500 \mathrm{mV} / \mathrm{div}$, and $100 \mathrm{mV} / \mathrm{div}$, respectively, for $y$-scale and in $10 \mathrm{~ms}$ for $x$-scale. Frequency spectrums were measured by using NI PCI-6251 DAQ board and LabVIEW software with 5 averages at RMS averaging mode. For clock settings of DAQ, one hundred samples were read at $1000 \mathrm{~Hz}$ rate. Frequency spectrums are shown in 0 $-45 \mathrm{dBV}_{\mathrm{rms}}^{2}$ for $y$-scale and in $0 \sim 500 \mathrm{~Hz}$ for $x$-scale.

The distribution of peak noise in frequency spectrum showed that the peak noise frequency had a tendency to increase linearity with $\sim 0.7 \mathrm{~Hz} /(\mathrm{m} / \mathrm{min})$ rate through $40 \sim$ $55 \mathrm{~m} / \mathrm{min}$ belt speed range. Also the resonance frequency was found to be $\sim 36 \mathrm{~Hz}$ at $47 \mathrm{~m} / \mathrm{min}$ belt speed as shown in Figure 3. However the nonlinearity was observed when the belt speed was approaching to resonance speed of $47 \mathrm{~m} / \mathrm{min}$. This is due to pulling effect; the tendency to maintain the constant peak noise frequency of $\sim 34.5 \mathrm{~Hz}$ in the vicinity of $36 \mathrm{~Hz}$ resonance frequency, through $40 \sim 55 \mathrm{~m} / \mathrm{min}$ belt speed range. Also multiple frequency peaks are observed, in frequency spectrum except resonance condition, due to multiple noise components.

\section{Noise Reduction Technique}

The signal, which contains measured weight information and noise while in operation, is picked up from the load cell sensor. In general, it will be advantageous to obtain better signal-to-noise ratio by limiting frequency bandwidth using narrower frequency limiting filters. However, this will eventually distort the input waveform, and the relatively shorter plateau of input square waveform will be obtained. When the belt speed is low, the pulse duration of input square waveform will be longer, and when the belt speed is high, the pulse duration will be shorter. Thus the figure of merit is determined using pulse width ratio, $R_{\mathrm{PW}}$, which is the ratio of top pulse width, $L_{\text {Top }}$, to bottom pulse width, $L_{\text {Bot }}$, of input waveform after passing frequency limiting filters as shown in (7) and in Figure 4.

$$
R_{\mathrm{PW}}=\frac{L_{\mathrm{Top}}}{L_{\mathrm{Bot}}} .
$$

3.1. Noise Reduction Algorithm. The input signal was filtered through LPF having variable cutoff frequency and slope controlling capability to obtain the bigger pulse width ratio and the more than minimum top pulse width of input signal depending on the belt conveyor speed. The cutoff frequency of LPF was chosen by tracking the peak noise frequency component and comparing with the predetermined value along with belt speed. And the slope of LPF was controlled by monitoring the pulse width ratio to keep more than minimum top pulse width of input signal. The predetermined value overrides to the calculated LPF cutoff frequency and slope unless the measured magnitude of noise frequency is lower than the predetermined value. This is to maintain stable noise rejection when the belt speed corresponds to off resonance frequency where multiple noise component presents in the noise spectrum. The block diagram showing this noise reduction (NR) process is shown in Figure 5 .

3.2. Variable Cutoff Frequency and Slope LPF. The proposed LPF having variable cutoff frequency and slope control capability is consisted with primary LPF for cutoff frequency control, which is followed by secondary 6 stages of LPF for slope control. The primary LPF adapted 8th-order elliptic filter having continuous variable cutoff frequency control capability to reject peak noise components in the wide noise frequency spectrum distribution. The secondary LPF adapted 6 stages of LPF having Sallen-Key topology to obtain bigger pulse width ratio while rejecting unwanted noise spectrum. The discrete switches having digital control capability were used to selectively control each stage of LPF. The primary LPF used the dedicated IC, LTC1066-1, which had the external clock-tunable feature for sharp cutoff frequency controlling. The secondary LPF used the 6-stage LPFs having staggered cutoff frequencies. The block diagram of proposed LPF is as shown in Figure 6. The microprocessor was used to control cutoff frequency and slope control.

\section{Noise Measurement}

The characteristics of proposed LPF having variable cutoff frequency were examined by varying input frequency. The effectiveness of the proposed noise reduction technique was evaluated by flowing actual mass on the belt conveyor and monitoring the mass information recovery from the noisy background. The peak noise frequency components were removed by primary LPF, and optimum pulse width ratio was controlled by secondary LPF using cutoff frequency slope control. The cutoff frequency of primary LPF was determined by analyzing noise frequency spectrum using the 9 bandpass filters during calibration stage. The passband frequency span of band-pass filters was $5 \mathrm{~Hz}$, and the range of frequency monitoring was from $17.5 \mathrm{~Hz}$ to $62.5 \mathrm{~Hz}$. In the initial stage, the cutoff frequency of primary LPF was to set to $65 \mathrm{~Hz}$ to cover unmonitored frequency band, and optimum pulse width ratio was controlled. The filter bypass switches in secondary LPF were used for LPF slope control. The top and bottom pulse widths of output signal pulse containing the test mass information were monitored by flowing test mass and selectively switching the combination of 4 LPF bypass switches in secondary LPF during calibration stage. The pulse width ratio was calculated from this width information, and the optimum switching logic was determined from the best pulse width ratio information.

\subsection{Characteristics of LPF Having Variable Cutoff Frequency.} The measured frequency response of primary filter, 8thorder elliptic low pass filter adapting LTC1066-1, showed attenuation characteristics as shown in Figure 7. Also the 

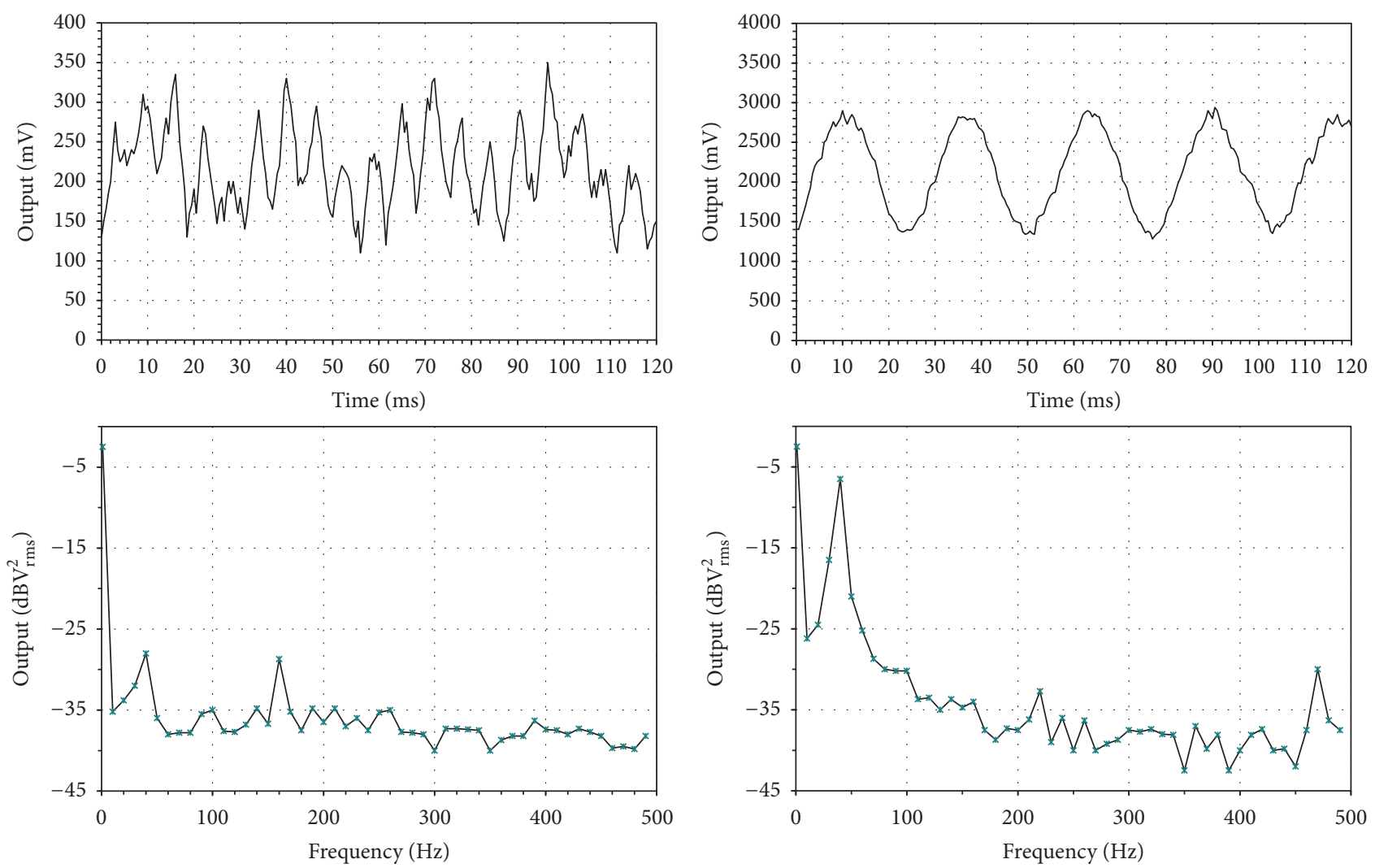

(a)

(b)
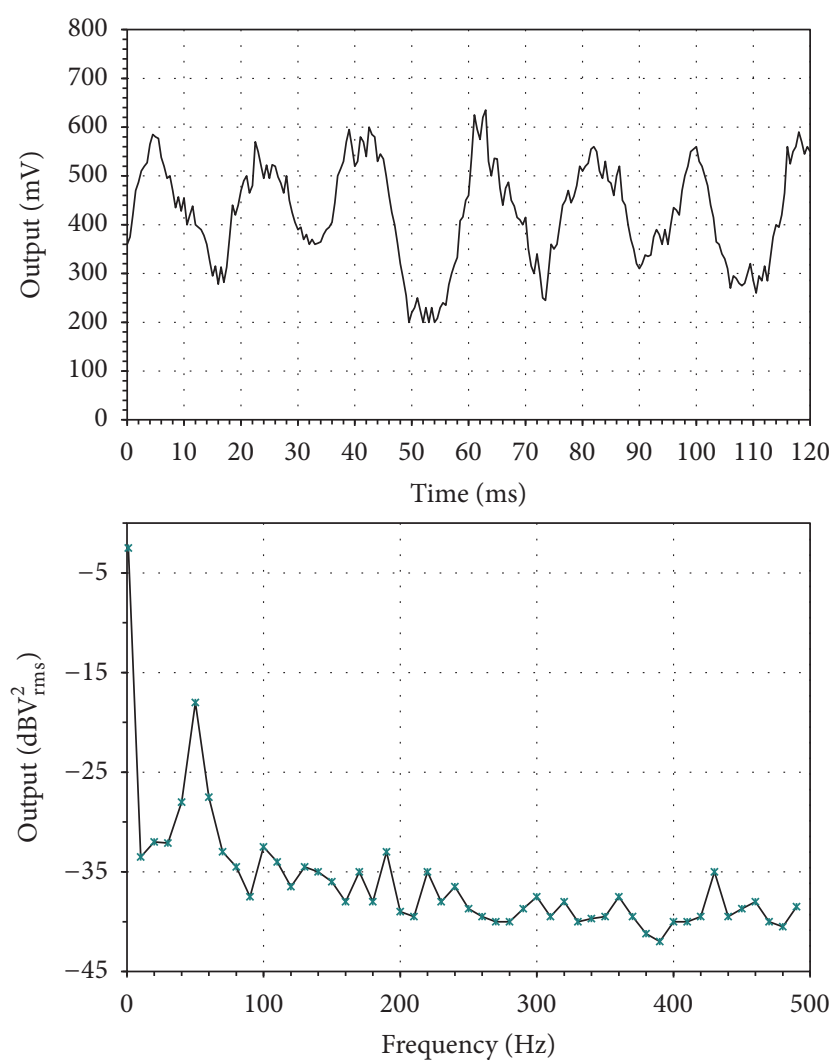

(c)

FIgURe 2: Noise waveforms in time (upper) and frequency (lower) domains. (a) $v_{c}=20 \mathrm{~m} / \mathrm{min}$. (b) $v_{c}=50 \mathrm{~m} / \mathrm{min}$. (c) $v_{c}=70 \mathrm{~m} / \mathrm{min}$. 


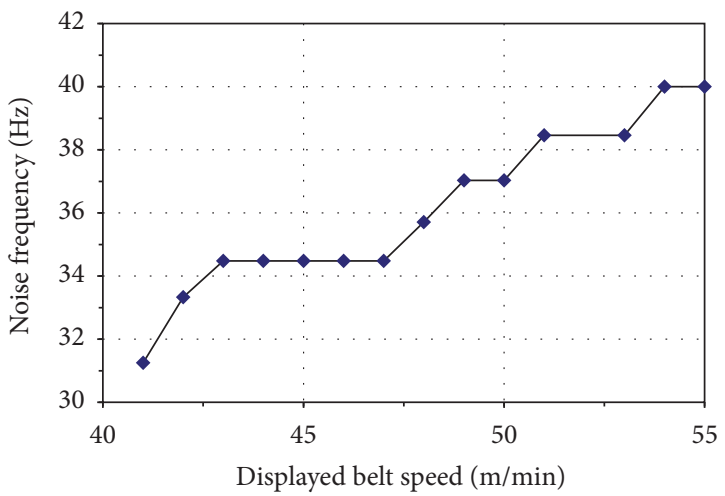

(a)

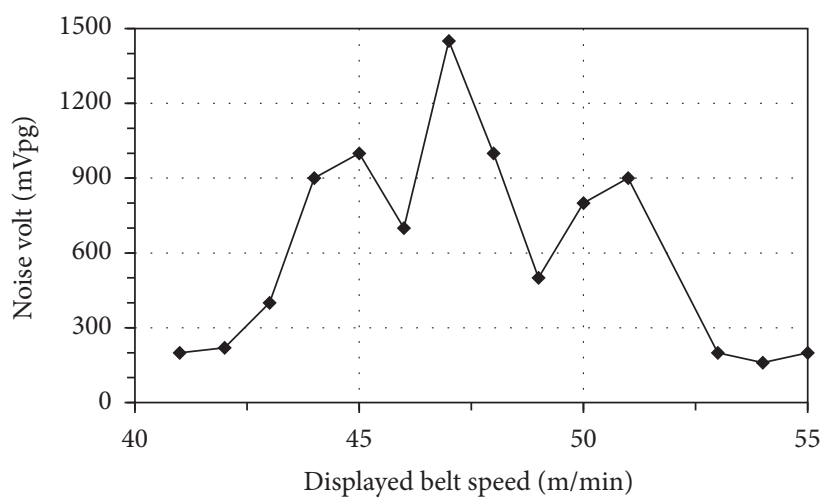

(b)

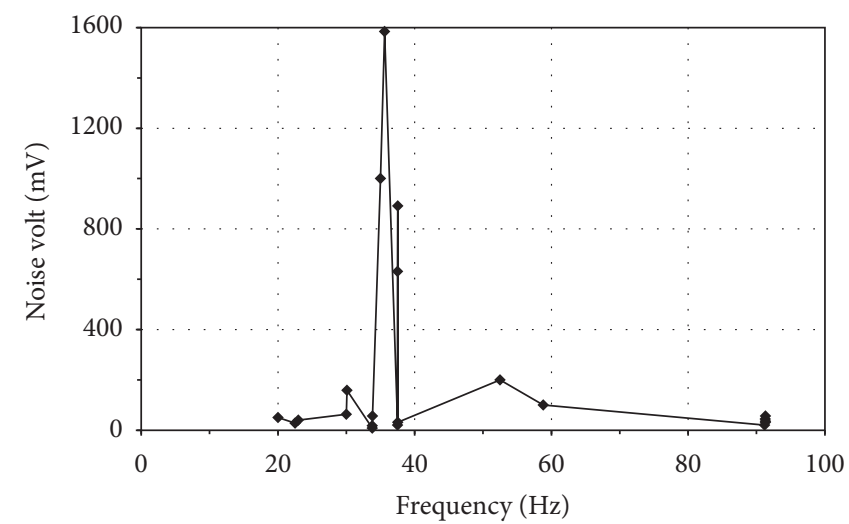

(c)

FIGURE 3: Noise intensity and frequency variation along with belt conveyor speed. (a) Peak noise frequency versus speed. (b) Noise intensity versus speed. (c) Noise intensity versus frequency.

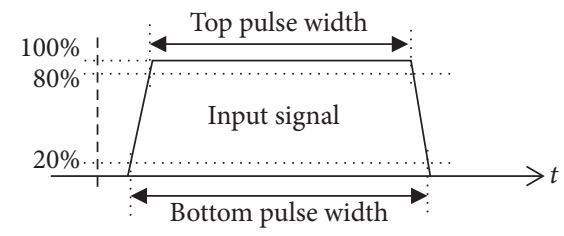

Figure 4: Definition of parameters in pulse width ratio.

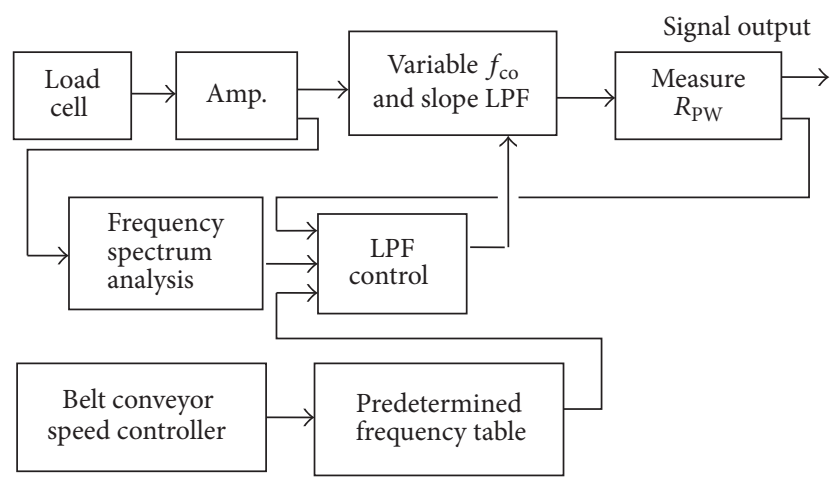

FIGURE 5: Block diagram showing noise reduction process by utilizing LPF with variable cutoff frequency and slope.

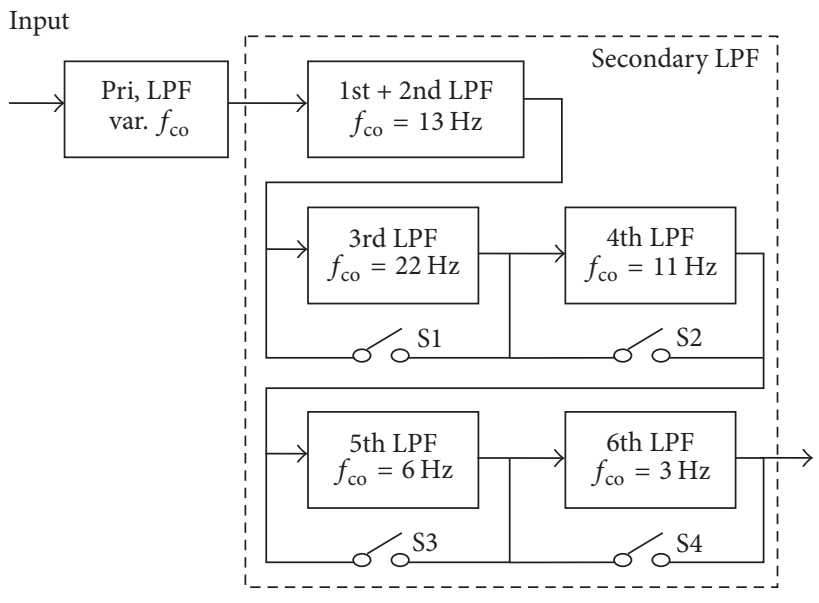

FIgURE 6: Block diagram of variable $f_{\text {co }}$ and slope LPF.

measured frequency responses of secondary filter are as shown in Figure 8.

4.2. Mass Measurement after Noise Reduction. The test mass of $50 \mathrm{~g}$ weight was flown to the belt conveyor, and two signals, received signal before noise reduction and recovered signal 


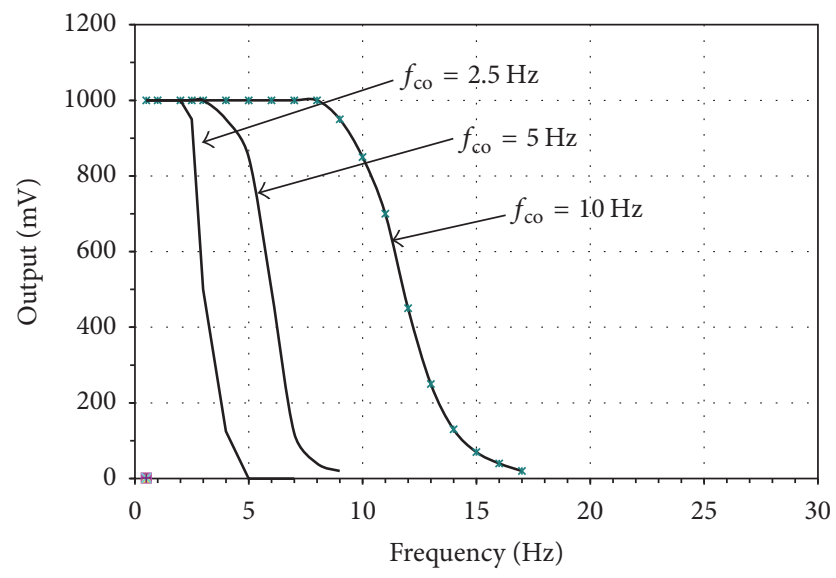

Figure 7: Measured frequency response of primary filter, 8th-order elliptic LPF, by varying cutoff frequency.

after noise reduction, were compared as shown in Figure 9. Two cases of belt conveyor speed were chosen, the first case with $10 \mathrm{~m} / \mathrm{min}$ speed having the least noise and the second case with $47 \mathrm{~m} / \mathrm{min}$ having the peak noise. Both cases showed that filtering was effective for recovering the mass measurement signal from the noisy environment.

In general, the signal-to-noise ratio improves by limiting the cutoff frequency of LPF. However the excessive limiting of LPF band will result in the deformed measurement signal waveform and consequently the degraded accuracy. Thus it is necessary to preserve the measurement signal waveform while rejecting the strong noise component. By using the noise reduction algorithm, the peak noise component is removed by the primary LPF, and the optimum pulse width ratio is deduced by the secondary LPF through slope control using selective switching of 4 LPF bypass switches by applying noise reduction algorithm.

The peak noise spectrum, $f_{\text {peak }}$, was found in around $36 \mathrm{~Hz}$ at $47 \mathrm{~m} / \mathrm{min}$ speed of belt conveyor during the noise measurement stage. This noise component was detectable in the band-pass filter having $32.5 \sim 37.5 \mathrm{~Hz}$ passband during frequency spectrum analysis. The cutoff frequency, $f_{\mathrm{co}}$, of the primary LPF was set to $20 \mathrm{~Hz}$, by using the formula $1.75 f_{\mathrm{co}}=$ $f_{\text {peak }}$, which attenuated more than $-40 \mathrm{~dB}$ to the peak noise component. The slope of measurement signal was controlled to remove the ripple, in top side of measured signal pulse waveform, by monitoring pulse width ratio $R_{\mathrm{PW}}$, and thus this provided the optimum pulse width ratio. This slope control was done, by switching off $\mathrm{S}_{1}$ and $\mathrm{S}_{2}$ and switching on $\mathrm{S}_{3}$ and $S_{4}$, in the secondary LPF when the belt conveyor speed was $47 \mathrm{~m} / \mathrm{sec}$. The effectiveness of noise reduction process was examined between fixed cutoff frequency and cutoff frequency using NR algorithm as shown in Figure 10. Here, the fixed control case is the controlling only cutoff frequency of primary LPF, and the case using noise reduction algorithm is controlling both cutoff frequency of primary LPF and slope of secondary LPF.

The measured waveform in fixed control case showed the sharp rise and fall time of measured pulse; however the ripple in the top side of measured waveform degraded the accuracy

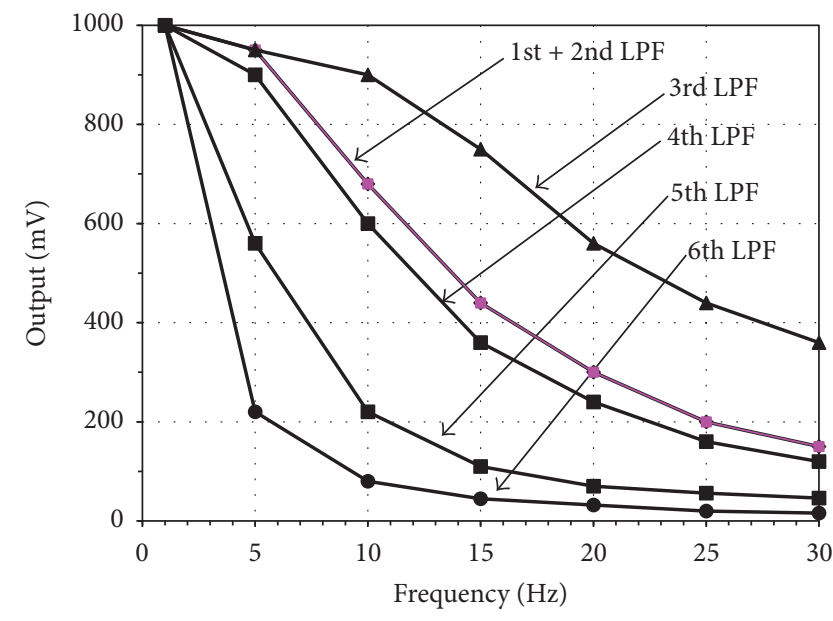

FIGURE 8: Measured frequency response of each stage in secondary filter, Sallen-Key topology LPF, having staggered cutoff frequencies.

of measurement information. The measured waveform using noise reduction algorithm showed the relatively longer rise and fall time of measured pulse; however the reduction of ripple in the top side of measured pulse enhanced the accuracy of measured signal. The pulse width ratio was measured using the $50 \mathrm{~g}$ test mass by applying the noise reduction algorithm as shown in Figure 11.

The pulse width ratio above $50 \%$ was obtained, through $10 \sim 80 \mathrm{~m} / \mathrm{min}$ speed range of belt conveyor up to $5 \mathrm{~Hz}$ of primary LPF cutoff frequency. However LPF cutoff frequency below $5 \mathrm{~Hz}$ severely degraded the pulse width ratio below $50 \%$. The recovered signal waveform using noise reduction algorithm showed better noise filtering than fixed cutoff frequency control with enhanced pulse width ratio, top pulse width over bottom pulse width.

\section{Conclusion}

Noise in load cell signal in an automatic weighing system based on a belt conveyor has been examined analytically and experimentally in time and frequency domains for the 10 $80 \mathrm{~m} / \mathrm{min}$ speed range of belt conveyor. The noise frequency spectrum showed multiple frequency peaks and increased nonlinearly, as the belt speed increased, with resonance frequency of $\sim 36 \mathrm{~Hz}$ at $47 \mathrm{~m} / \mathrm{min}$ belt speed. The noise reduction process using noise reduction algorithm, by sharply rejecting peak noise frequency component using primary LPF and forming optimum pulse width ratio using secondary LPF through filter slope control, was applied to the $10 \sim 80 \mathrm{~m} / \mathrm{min}$ speed range of belt conveyor. The cutoff frequency of primary LPF was calculated by the formula $1.75 f_{\text {co }}=f_{\text {peak }}$ to provide $-40 \mathrm{~dB}$ attenuation against the peak noise frequency component, using the 9 band-pass filters for frequency analysis and elliptic phase 8th-order LPF having variable cutoff frequency for sharp noise rejection, during calibration stage. The selective control of 4 LPF bypass switches in secondary LPF was used for LPF slope control to obtain optimum pulse width ratio for enhanced accuracy. The effectiveness of the proposed noise reduction process was evaluated by 


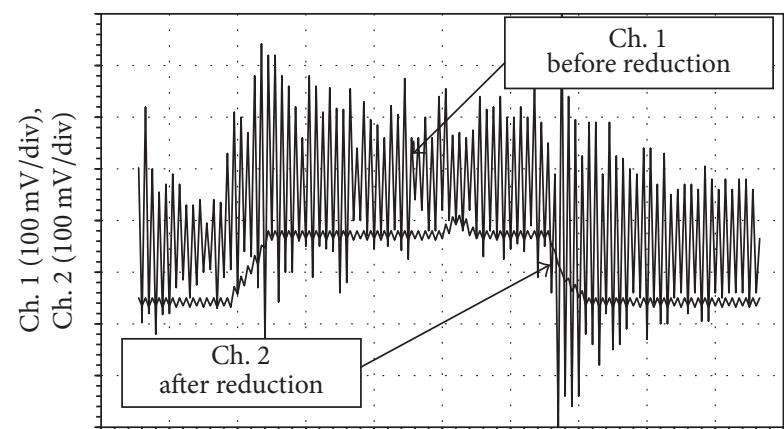

Time (500 ms/div)

(a)

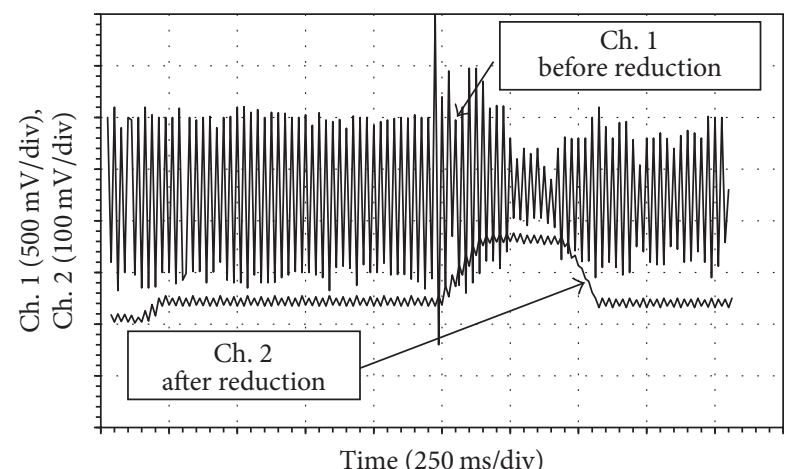

(b)

FIGURE 9: $50 \mathrm{~g}$ mass measurement signals before and after noise reduction. (a) $v_{c}=10 \mathrm{~m} / \mathrm{min}$. (b) $v_{c}=47 \mathrm{~m} / \mathrm{min}$.

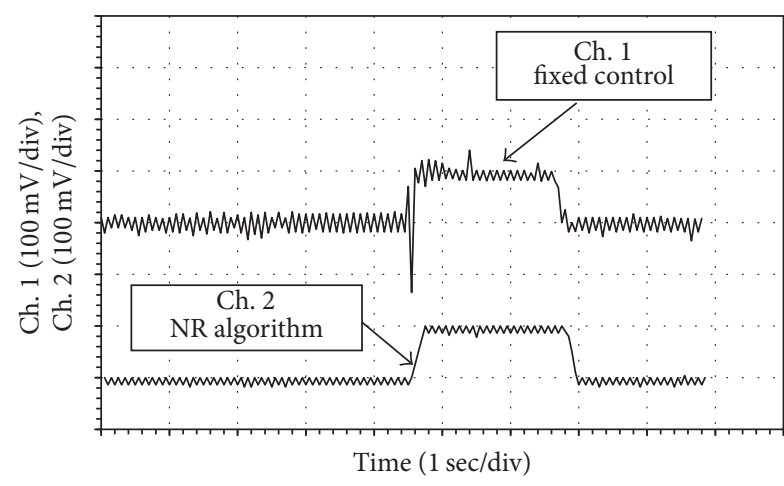

(a)

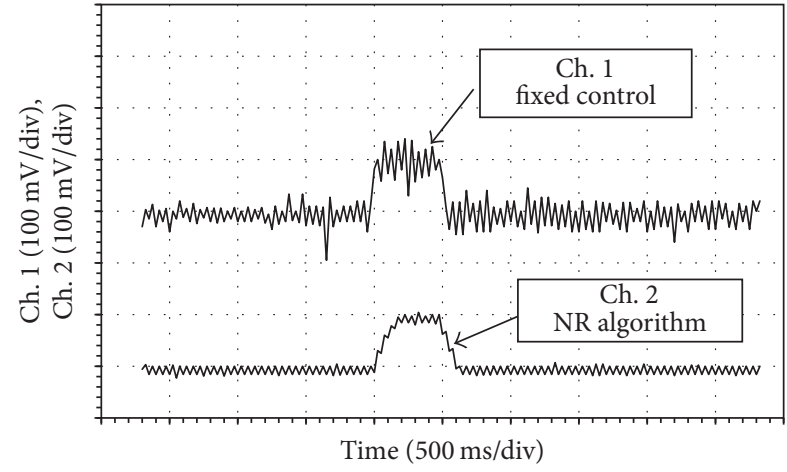

(b)

FIGURE 10: $50 \mathrm{~g}$ mass measurement signals between fixed cutoff frequency control and cutoff frequency control using NR algorithm. (a) $v_{c}=10 \mathrm{~m} / \mathrm{min}$. (b) $v_{c}=47 \mathrm{~m} / \mathrm{min}$.

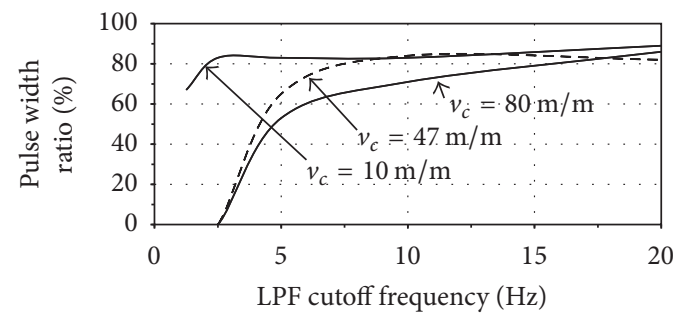

(a)

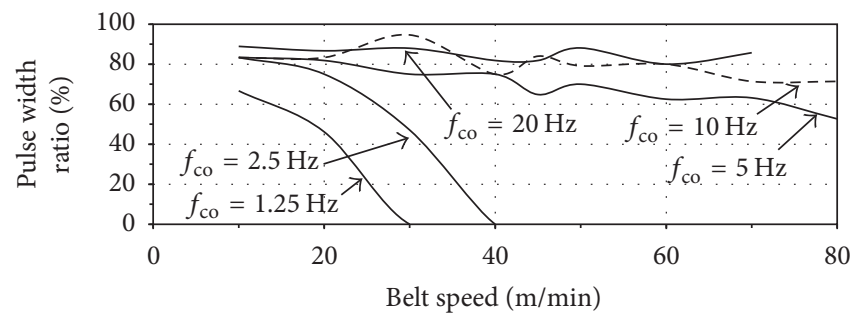

(b)

FIGURE 11: Pulse width ratio of $50 \mathrm{~g}$ mass measurement signals between cutoff frequency of primary LPF and belt conveyor speed.

feeding $50 \mathrm{~g}$ test mass and monitored accordingly. The result showed that noise reduction process using noise reduction algorithm had better pulse width ratio, implying better accuracy, than fixed cutoff frequency control for recovering the mass information from the noisy environment. The pulse width ratio above $50 \%$ was obtained, through $10 \sim 80 \mathrm{~m} / \mathrm{min}$ speed range of belt conveyor up to $5 \mathrm{~Hz}$ of primary LPF cutoff frequency. However LPF cutoff frequency below $5 \mathrm{~Hz}$ severely degraded the pulse width ratio below $50 \%$.

\section{Conflicts of Interest}

The author declares that there are no conflicts of interest regarding the publication of this paper.

\section{Acknowledgments}

This work was supported by Incheon National University Research Grant in 2016. 


\section{References}

[1] D. L. Okopnik and R. Falate, "Usage of the DFRobot RB-DFR49 infrared sensor to detect maize seed passage on a conveyor belt," Computers and Electronics in Agriculture, vol. 102, pp. 106111, 2014.

[2] M. Sitti, I. Bozma, and A. Denker, "Visual tracking for moving multiple objects: an integration of vision and control," in Proceedings of the IEEE International Symposium on Industrial Electronics, pp. 535-540, Athens, Greece.

[3] E. Hamzeloo, M. Massinaei, and N. Mehrshad, "Estimation of particle size distribution on an industrial conveyor belt using image analysis and neural networks," Powder Technology, vol. 261, pp. 185-190, 2014.

[4] S. Jeong, Y. Yang, K. Lee, J. Kang, and D. Lee, "Vision-based automatic system for non-contact measurement of morphometric characteristics of flatfish," Journal of Electrical Engineering \& Technology, vol. 8, no. 5, pp. 1194-1201, 2013.

[5] A. Heyduk, "Laser triangulation in 3-dimensional granulometric analysis," Archives of Mining Sciences, vol. 61, no. 1, pp. 15-27, 2016.

[6] B. Nimsiriwangso, S. Kummool, A. Julsereewong, and P. Ukakimaparn, "Automatic weighing machine for improving competitiveness of Thai SMEs in seafood cold storage business," in Proceedings of the 8th Annual IEEE/SICE International Symposium on System Integration, SII 2015, pp. 771-776, jpn, December 2015.

[7] A. Waal, S. Mercer, and B. J. Downing, "Online fruit weighing using a $500 \mathrm{MHZ}$ waveguide cavity," Electronics Letters, vol. 24, no. 4, pp. 212-213, 1988.

[8] P. Bourgeois, "Automatic selection, weighing and conveyingquality and quantity by remote control," Institution of Production Engineers Journal, vol. 34, no. 10, p. 670, 1955.

[9] P. Belsham, "Process-weighing automation for consistent performance," Electronics Power, vol. 30, no. 3, pp. 225-226, 1984.

[10] M. Niedzwiecki, M. Meller, and P. Pietrzak, "System identification based approach to dynamic weighing revisited," Mechanical Systems and Signal Processing, vol. 80, pp. 582-599, 2016.

[11] T. Bainbridge, "Electronic weigh counting for maximum efficiency," Electronics and Power, vol. 21, no. 12, pp. 735-736, 1975.

[12] P. Pietrzak, M. Meller, and M. Niedźwiecki, "Dynamic mass measurement in checkweighers using a discrete time-variant low-pass filter," Mechanical Systems and Signal Processing, vol. 48, no. 1-2, pp. 67-76, 2014.

[13] P. Castellini, "Vibration measurements by tracking laser doppler vibrometer on automotive components," Shock and Vibration, vol. 9, no. 1-2, pp. 67-89, 2002.

[14] J. Dybala and R. Zimroz, "Rolling bearing diagnosing method based on empirical mode decomposition of machine vibration signal," Applied Acoustics, vol. 77, pp. 195-203, 2014.

[15] M. Fabbri, P. L. Ribani, and D. Zuffa, "Design and testing of a magnetic suspension for a $90^{\circ}$ horizontal bend conveyor," COMPEL - The International Journal for Computation and Mathematics in Electrical and Electronic Engineering, vol. 34, no. 1, pp. 380-396, 2015.

[16] H.-W. Ma, H.-W. Fan, Q.-H. Mao, X.-H. Zhang, and W. Xing, "Noise reduction of steel cord conveyor belt defect electromagnetic signal by combined use of improved wavelet and EMD," Algorithms, vol. 9, no. 4, article 62, 2016.

[17] F. Widdis, "The measurement and suppression of noise," Electronics \& Power, vol. 12, no. 5, p. 163, May 1966.
[18] P. Shi, C. Su, and D. Han, "Fault diagnosis of rotating machinery based on adaptive stochastic resonance and AMD-EEMD," Shock and Vibration, vol. 2016, Article ID 9278581, 11 pages, 2016.

[19] Q. Huang, S. Chen, M. Huang, and Z. Guo, "Adaptive active noise suppression using multiple model switching strategy," Shock and Vibration, vol. 2017, pp. 1-6, 2017.

[20] P. Ligocki and B. Karolewski, "Modelling of dynamics of belt conveyors with squirrel cage induction motors," Przeglad Elektrotechniczny, vol. 85, no. 3, pp. 56-58, 2009.

[21] A. V. Rocha, G. J. Franca, M. E. Dos Santos, H. De Paula, and B. J. C. Filho, "Increasing long-belt-conveyor availability by using fault-resilient medium-voltage ac drives," IEEE Transactions on Industry Applications, vol. 48, no. 5, article no. 32, pp. 1708-1716, 2012.

[22] Y. Shen and X. Xia, "Adaptive parameter estimation for an energy model of belt conveyor with DC motor," Asian Journal of Control, vol. 16, no. 4, pp. 1122-1132, 2014.

[23] N. Vijayakumar, G. Eltaliawi, and A. Seeliger, "Co-simulation of complex belt conveyor drive systems," in Proceedings of the 5th IET International Conference on Power Electronics, Machines and Drives, PEMD 2010, April 2010.

[24] M. Niedzwiecki and P. Pietrzak, "High-precision FIR-modelbased dynamic weighing system," IEEE Transactions on Instrumentation and Measurement, vol. 65, no. 10, pp. 2349-2359, 2016.

[25] J. Robbins, "Silent variable-speed treadmill," Journal of the Society of Motion Picture Engineers, vol. 34, no. 6, pp. 632-636, 1940.

[26] X.-P. Jiang and G.-Q. Cao, "Belt conveyor roller fault audio detection based on the wavelet neural network," in Proceedings of the 11th International Conference on Natural Computation, ICNC 2015, pp. 954-958, August 2015.

[27] T. Qiao, W. Liu, Y. Pang, and G. Yan, "Research on visible light and infrared vision real-time detection system for conveyor belt longitudinal tear, IET Science," Meas. Tech, vol. 10, no. 6, pp. 577-584, 2016.

[28] Y. Yunyue, "Application of linear electric motors in the postal mechanical systems," in Proceedings of the 5th International Conference on Electrical Machines and Systems, ICEMS 2001, pp. 964-967, August 2001.

[29] S. Koyanaka and K. Kobayashi, "Incorporation of neural network analysis into a technique for automatically sorting lightweight metal scrap generated by ELV shredder facilities," Resources, Conservation and Recycling, vol. 55, no. 5, pp. 515523, 2011.

[30] T. Umemoto, Y. Sasamoto, M. Adachi, and Y. Kagawa, "Improvement of accuracy for continuous mass measurement in checkweighers with an adaptive notch filter," in Proceedings of the SICE Annual Conference 2008 - International Conference on Instrumentation, Control and Information Technology, pp. 10311035, jpn, August 2008.

[31] U. A. Rosa, T. S. Rosenstock, H. Choi et al., "Design and evaluation of a yield monitoring system for pistachios," Transactions of the ASABE, vol. 54, no. 5, pp. 1555-1567, 2011.

[32] Y. Sasamoto, T. Umemoto, M. Adachi, and Y. Kagawa, "Frequency analysis method using the adaptive algorithm and application to dynamic measurement of mass and weight," in Proceedings of the SICE (Society of Instrument and Control Engineers)Annual Conference, SICE 2007, pp. 37-41, September 2007. 
[33] A. T. EL-Sayed and H. S. Bauomy, "Nonlinear analysis of vertical conveyor with positive position feedback (PPF) controllers," Nonlinear Dynamics, vol. 83, no. 1-2, pp. 919-939, 2016.

[34] R. Tasaki, T. Yamazaki, H. Ohnishi, M. Kobayashi, and S. Kurosu, "Continuous weighing on a multi-stage conveyor belt with FIR filter," Measurement, vol. 40, no. 7-8, pp. 794-799, 2007. 


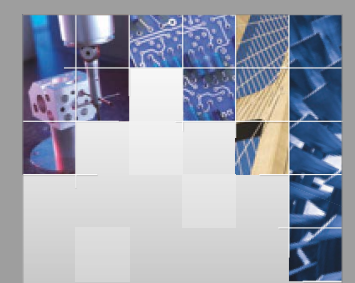

\section{Enfincering}
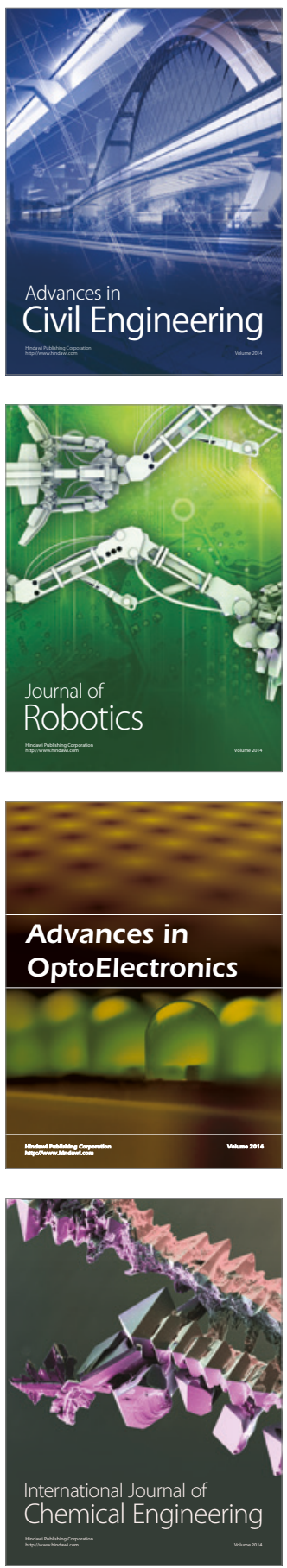

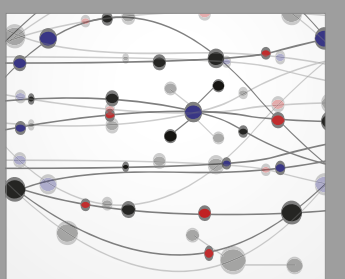

The Scientific World Journal

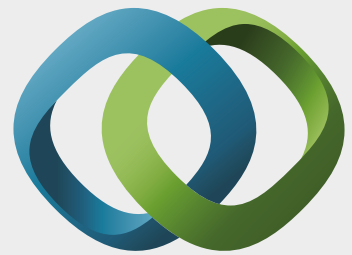

\section{Hindawi}

Submit your manuscripts at

https://www.hindawi.com
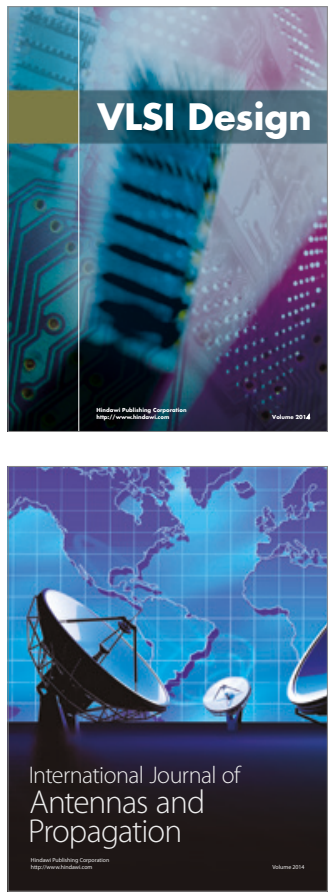

\section{Rotating}

Machinery
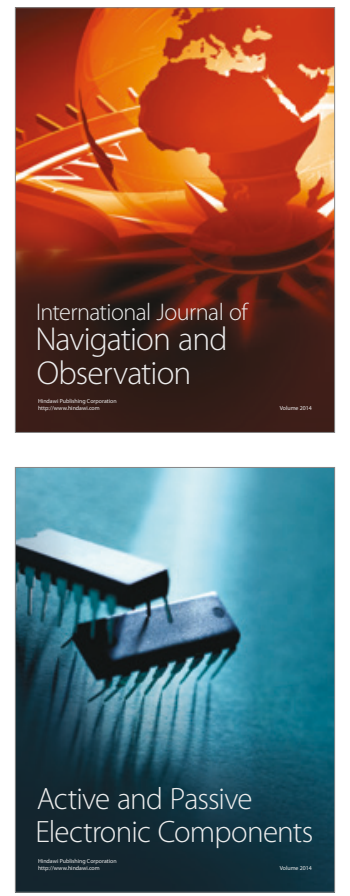
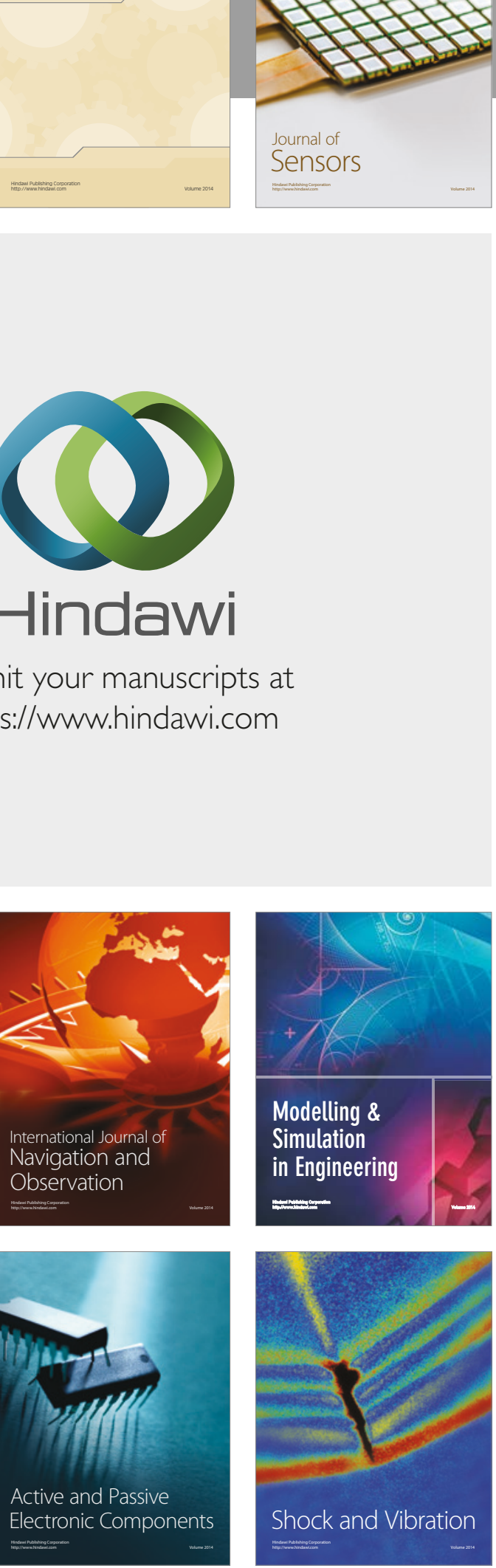
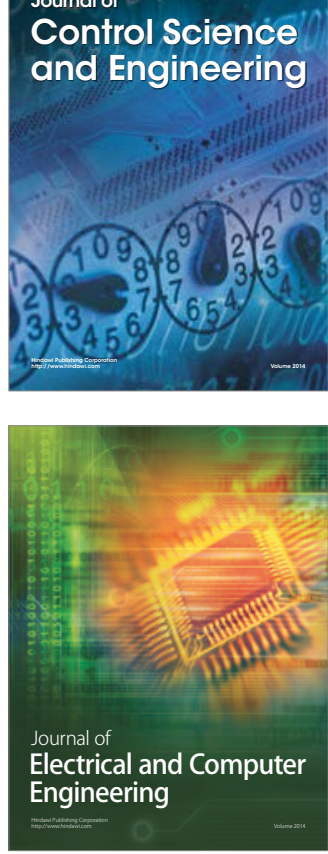

Distributed

Journal of

Control Science

and Engineering
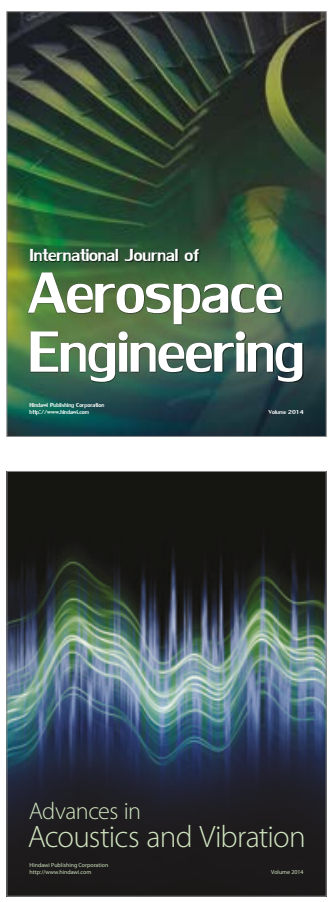

Sensor Networks 